\title{
Extended Middle Fossa Approach for Trigeminal Schwannoma Resection
}

\author{
Baha'eddin A. Muhsen ${ }^{1, *}$ Edinson Najera ${ }^{1}$ Hamid Borghei-Razavi ${ }^{1}$ Badih Adada ${ }^{1}$ \\ 1 Department of Neurosurgery, Braathen Center, Cleveland Clinic \\ Address for correspondence Badih Adada, MD, 3121 Cleveland Clinic \\ Florida, Weston, Florida, United States \\ Blvd, Weston, FL 33331 (e-mail: ADADAB@ccf.org)
}

J Neurol Surg B Skull Base 2022;83(suppl S3):e615.

\begin{abstract}
Keywords

- trigeminal schwannoma

- cavernous sinus

- extended middle fossa approach

- peeling of middle cranial fossa

- anterior petrosectomy

Trigeminal schwannomas are rare benign tumors, it is second most common intracranial schwannomas after vestibular schwannomas. The management includes not limited to observation, stereotactic radiosurgery/radiotherapy, and/or surgical resection. Tumor size and patient clinical status are the most important factors in management.

In this video, we describe the technical nuances of an extended middle fossa approach for large trigeminal schwannoma with cavernous sinus extension resection. A 44-yearold right-handed female with several months' history of progressive right facial paresthesia and pain in the distribution of V3 mainly. On physical examination, she had decreased sensation to light touch over the right V1 to V3 distribution with loss of cornel reflex. The brain MRI showed $3.5 \mathrm{~cm}$ bilobed mass extends from the pontine root entry zone to the cavernous sinus. Craniotomy was performed and followed by middle fossa dural peeling, peeling of temporal lobe dura away from the wall of the cavernous sinus, extradurally anterior clinoidectomy, drilling of the petrous apex, coagulation of superior petrosal sinus followed incision of the tentorium up to the tentorial notch with preservation the fourth cranial nerve, and tumor dissected away from V1 and then gradually removed from the superior wall of the cavernous sinus.

The technique presented here allows for complete tumor resection, safe navigation through the relative cavernous sinus compartments, and minimizes the possibility of inadvertent injury to the cranial nerves.

The postoperative course was uneventful except for right eye incomplete ptosis from the swelling. Her facial pain subsided after the surgery without any extra ocular movement impairment.

The link to the video can be found at: https://youtu.be/zxi2XK2R9QU.
\end{abstract}

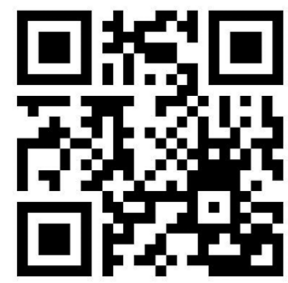

Current affiliation: Division of Neurosurgery, Department of Surgery, King Hussein Cancer Center, Amman, Jordan.

received

September 16, 2020

accepted

October 31, 2020

published online

June 22, 2021
Conflict of Interest

None declared.

www.thieme.com/skullbasevideos

www.thieme.com/jnlsbvideos

(c) 2021. The Author(s).

This is an open access article published by Thieme under the terms of the Creative Commons Attribution-NonDerivative-NonCommercial-License, permitting copying and reproduction so long as the original work is given appropriate credit. Contents may not be used for commercial purposes, or adapted, remixed, transformed or built upon. (https://creativecommons.org/ licenses/by-nc-nd/4.0/)

Georg Thieme Verlag KG, Rüdigerstraße 14, 70469 Stuttgart, Germany 